\title{
Fasciolosis disease in cattle and sheep in Karakalpakstan in 2015-2020, prevalence, epizootology and treatment methods and results obtained
}

\author{
Shavkat Avezimbetov \\ Candidate of Veterinary Sciences, Associate Professor. \\ Nukus branch of Samarkand Institute of Veterinary Medicine \\ Odilbek Dosumbetov. \\ Student
}

\begin{abstract}
Fastioliosis in the Republic of Karakalpakstan in acute, chronic and mixed course, acute course of F. gigantica-induced fasciolosis in sheep, clinical signs of fasciolosis, adult fasciolia, definitive host-infected fasciola larvae, possible factors, diagnosis, results of complete dissection of the liver in animals that died from the disease, drugs for the treatment of fasciolosis are described.
\end{abstract}

Keywords: Fastiolyosis, F.gigantica, definitive host, invasive intensity, parasite, fibrinogen, fasciola, hypotension, atony, adolescaria, mollusks, fasciola eggs.

\section{Introduction}

The purpose of the study is to improve the disease, its prevalence, epizootiology and treatment in the Republic of Karakalpakstan.

The urgency is that in the Republic of Karakalpakstan fasciolosis is acute, chronic and mixed. The acute course of the disease occurs as a result of parasitism of $\mathrm{F}$. gigantica young forms for 90-120 days and more. When the intensity of the invasion is high, the acute course of fasciolosis leads to the death of sheep and goats, and even cattle. This condition is more common in F.gigantica-induced disease.

In animals that do not die from the acute course of fasciolosis, fasciolia in the liver tissue pass into the bile ducts and mature, resulting in chronic course of the disease as a result of prolonged parasitism excites. When the conditions for keeping and feeding animals are good, chronic fasciolosis is considered somewhat safer than the disease that occurs in the acute course.

In the case of F. gigantica disease in animals that have survived the acute course of fasciolosis, the mixed course of fasciolosis begins from 100 to 110 days if the intensive infestation with fasciola lasts for a long time.

During mixed flow, young fasciolia are found in the liver tissue and adult fasciolia in the hepatic bile ducts. Because of this, the mixed flow of fasciolosis is also angerous.

\section{Main part}

According to our research, the acute course of fasciolosis is observed during the life of young fasciolia in the liver tissue of animals, the extent of which depends on the intensity of the invasion, the short-term infection of large numbers of fasciolia larvae, the first or repeated infection of animals with fascioliasis. in the acute course I first found disruption of the liver tissue, its capsule, blood vessels, and then the walls of the hepatic tract.

The results obtained show that in the territory of Karakalpakstan the acute influx of $F$. gigantica-induced fasciolosis among sheep is more severe than in other regions. It has no fibrinous coating on the surface of the liver, and no fibrinous fibers in its parenchyma. Due to the lack of fibrinogen, bleeding from blood vessels injured in the liver tissue by young fasciolia does not stop. Therefore, in the pathways of young fasciolas, which are in constant motion in the liver parenchyma, as well as in the bile ducts and gallbladder (due to the passage of fasciolia), blood fluid or its associations accumulate, and bloody exudate in the abdominal cavity. In sheep artificially infested with F. gigantica's adolescariae, due to parasitization of young fasciolas for 80 days, microscopically, large but immature trematodes with a body length of 23-27 mm and a width of $4 \mathrm{~mm}$ are exposed to liver parenchyma and blood vessels. As a result, deep wounds appear in the liver, which are enlarged relative to the size of the organ. As the fasciolia begins to penetrate the walls of the hepatic bile ducts into adulthood, the pathological process becomes more compli blood fluid and blood associations can accumulate in the gallbladder.I recommend that such a very severe acute course of fasciolosis be called a "parenchymal or tissue" form of fasciolosis and that it be introduced into science and practice.

In such a course of the disease are simultaneously parasitized in the liver parenchyma of the animal many young, its bile ducts and fasciolia grown in the gallbladder. Such a course of the disease occurs as a result of prolonged intensive infestation of the animals with fasciolia, and it is usually observed from the last month of the autumn season to the middle of the winter season, and is severe.

Clinical signs. The manifestation of clinical signs of fasciolosis depends on the number, age, type of fasciolia parasitizing in the main host organism of its pathogens, as well as the type of animals, their physiological condition, storage and feeding conditions.

Young fasciolias parasitizing in liver tissue destroy the blood vessels and tissues in it during growth, form 
many wounds in the liver, poison the body with metabolic products, and provoke an acute course of fasciolosis. In this form of the disease, the mucous membranes of the eyes of animals are whitened, as well as an increase in body temperature, palpitations and rapid breathing. As a result of the accumulation of large amounts of blood serum in the abdominal cavity, the abdominal part of the animal begins to sag. When I lifted the abdomen up with the surface of my hand and then lowered it quickly, I felt that there was fluid in it. The animal's appetite decreases, and then it disappears completely, the activity of the digestive organs is disturbed, resulting in increased intoxication, drinking, the animal is unable to get up from its weakened position, dies from indifference to external influences. A similar situation was observed in the mixed course of fasciolosis when the intensity of the invasion was strong

Sexually mature fasciolae inflame the hepatic bile ducts, poisoning the animal's body with metabolic products. Accumulation of bile in the bile ducts and gallbladder has led to yellowing of the mucous membranes and chronic course of the disease. Animals begin to lose appetite and lose weight, their young lag behind in growth. In chronic fasciolosis, cattle and sheep, in some cases under the jaw of goats, appear cold tumors in the chest, hypotension and atony of the anterior abdominal parts, diarrhea cated, the liver becomes larger in size, its parenchyma, bile ducts and cases of diarrhea and constipation alternate. Abortion is sometimes observed in pregnant animals.

According to our many years of observations, especially acute flow fasciolosis caused by F. gigantica and also its mixed flow is much more severe, resulting in a high mortality rate among infected animals.

Pathogenesis. The pathogenic effect of fasciolae on the host organism begins with the movement of their larvae towards the liver, followed by the transition to the liver parenchyma. Parasitic larvae isolated from the adolescent shells injure the intestinal mucosa, intestinal wall, blood vessels. Such tiny fasciolia, which pierce the liver capsule and fall into its parenchyma through the blood vessels, open many pathways in the liver tissue during growth and, due to their action, injure the blood vessels in it, the liver tissue. Later, as the fasciolia grow, the size of the lesions increases, and the disruption of the liver parenchyma becomes more pronounced. Before maturation, young fasciolas about $2.0-3.0 \mathrm{~cm}$ pierce the hepatic bile ducts and fall into its path and gallbladder. As a result of the accumulation of adult fasciolia, bile fluid accumulates in the bile ducts of the liver and in the gallbladder. Large amounts of accumulated bile fluid begin to be absorbed into the bloodstream and thus spread throughout the body. As a result, the mucous membranes of the previously white eyes begin to turn yellow. Insufficient intestinal fluid intake also has a negative effect on the digestive system. In some cases, young fasciolia are trapped in other organs along the bloodstream, but in these organs, such as the lungs, the parasites in the spleen are encapsulated before they mature.

Due to the movement of fasciola larvae infected with the definitive host throughout its body, pathogenic microbes in the gut pass to the internal organs, primarily the liver. Therefore, the appearance of small pus in this organ was observed. The host organism is poisoned by unnecessary products formed as a result of metabolism in the body of parasites of different ages and their undigested food residues in the midgut. Such toxins are absorbed into the bloodstream and spread throughout the body, adversely affecting the functioning of all organ systems.

Pathological and anatomical changes. The carcasses of animals that have died or been forcibly slaughtered as a result of fasciolosis are thin, the integrity of the skin is intact, the wool coat has lost its luster, and the wool is easily separated from the skin. The mucous membranes of the eyes, mouth, anal opening whitens in the acute course of fasciolosis. In chronic disease, the submandibular, mammary glands become enlarged; when the skin is arched, infiltration is observed under it, there is no layer of fat under the skin or it is poorly developed, visible mucous membranes appear yellowish or pale; a certain amount of serum accumulates in the chest and abdominal cavities. The liver is slightly enlarged in size, its bile ducts dilate and become inflamed, the liver bulges from the surface, the gallbladder swells; when the bile ducts are ruptured, they show a large number of adult fasciolas, which can also be found in the fluid in the gallbladder. When the bile fluid is examined by a series of washing methods, a large number of fasciola eggs in the sediment are visible under a microscope. If chronic fasciolosis lasts for a long time, the walls of the bile ducts thicken, and the accumulated lime and salts in them form "stones" of various sizes, yellowish in color.

The most important pathological process is observed in the liver in animals that die from acute exacerbation of fasciolosis. Its size increases several times, its surface is uneven, mostly covered with a fibrinous membrane, which is attached to the capsule of the liver. The edges of the liver are uneven, in which cirrhosis is strongly developed, due to which the consistency of the liver is hard, it is difficult to cut. In the liver parenchyma, due to the relentless movement of young fasciolas, many wounds are visible in its capsule, which contain mobile young parasites that protrude from the wounds to the surface of the liver. No significant pathological changes are observed in the hepatic bile ducts. The portal glands of the liver are enlarged due to the allergic reaction of parasites, the body's resistance to them. In the conditions of the Republic of Karakalpakstan, as mentioned above, blood clots form in wounds in the liver parenchyma, bile ducts, gallbladder.

Even with F.gigantica, infestation of all farm animals is inevitable throughout the year. However, the range of intermediate hosts of this trematode is much wider, and in the course of its parthenogenetic development from large limneids in Uzbekistan, as mentioned above, 4 species of mollusks - L. auricularia, L. bactriana, L. subddisjuncta, L. impura. These mollusks are mainly found in lakes (springs) on the banks of rivers, where plants such as reeds and lux grow. It is in these places that farm animals are kept almost all year round. Stable water 
lakes from such water bodies are very dangerous because in the body of the plants that grow in them accumulate a large number of adolescariae, which are formed from cercariae, which are constantly separated from mollusks infected with F.gigantica parthenites.

When 100 specimens of molluscs in this biotope were kept in dark, calm water for 1.5 hours, it was noted that F. gigantica cercariae separated from 37 specimens and that they quickly began to form adolescariae. In dangerous biotopes of such mollusks, in the autumn, even if their water dries out, the adolescariae in the plant body can retain their viability for a long time.

\section{Conclusion}

Many years of observations show that the damage of animals due to winter invasion stored in intermediate hosts of F. gigantica is less severe, it is possible that parthenites developing in its intermediate hosts show their strong pathogenic effect during the transition of mollusks to winter anabiotic state, therefore in early spring among the extinct limneids, those infested with the larvae of this trematode are rare. Adding more clarity to this issue requires special research.

The invasion caused by the infestation of mollusks this year has led to an increase in the incidence of fascioliasis in definitive hosts from the second half of summer throughout the fall season. Therefore, the acute course of fasciolosis caused by F. gigantica begins in autumn and peaks in early winter. Even in the first half of winter, deaths from fasciolosis among animals are observed. In this case, fasciolosis occurs in both acute and chronic currents. In the warm winter, fascioliosis of animals lasts longer in pasture conditions. This epizootiological situation is typical of diseases caused by both types of fasciola.

Farm animals of all types and ages are affected by fasciolosis. It is heavier in young sheep and cattle than in older animals. Goats, like other ruminant mammals, are less resistant to fasciolosis. If treatment for fasciolosis is not carried out in a timely manner or at all, the rate of fascia infection due to reinvasion and superinvasion will increase with the age of the animal. The course of fasciolosis and all its specific epizootiological features are closely related to the abiotic and biotic, including anthropogenic factors of the region. They include the average annual temperature, humidity and salinity of soil and water, the number and type of infected animals, their migration from one area to another, the size and ecological status of pastures, the number of mollusk biotopes, the existing hydrological regime and the density of intermediate hosts; the degree of infestation of fasciola with parthenites, the factors that ensure or hinder the development of fasciola larvae, including the degree of implementation of prescribed measures against fasciolosis, and others.

Factors contributing to the spread of fasciolosis. The spread of fascioliasis pathogens from one region to another or from one region to another, or even from one state to another, occurs due to various environmental factors. The transfer of fasciolosis-infected animals and hay and other roughage collected from unhealthy areas to healthy areas through the market system leads to the emergence of a new outbreak of the disease due to human activity. The spread of fasciolosis to other areas is also caused by the flow of water, one of the other abiotic factors. The long-distance migration of cercariae and mollusks infected with them by intermediate hosts of the pathogen leads to the formation of new foci of fasciolosis. Molluscs infested with F.gigantica parthenites are also spread by floodwaters to biotopes in a region other than the habitat in which they live.

Diagnosis of fasciolosis: The diagnosis of fasciolosis is made during the life of the animal based on clinical signs of the disease, epizootiological data and the results of special laboratory tests. To determine the chronic form of the disease, fecal samples taken from the rectum of animals are examined by sequential washing. Fastiola eggs should be distinguished from eggs of paramphistomats. Fastiola eggs are orange in color and are larger than the eggs of paramphistomats, which have a gray appearance. In dead animals, the liver is completely dissected, the sediment is washed several times to make it clear, and examined by placing it on Petri dishes. The type, age and number of collected fasciolas are determined.

Based on the age and number of found fasciolia, pathological changes in the liver and some other organs, it is determined in which course the fasciolosis occurred.

I recommend the following medications to treat fasciolosis. All albendazole (albene, albendazole, albenol, albazen, albendex, unimint, etc.), rolenol, brontel, clozantel, kombitrem, fascicide, etc. can be used for such therapeutic chemicals in accordance with the instructions.

It should be noted that all albendazole drugs are effective in the adult form of fascioliasis, ie chronic fasciolosis, which they cause. According to my research, when the intensity of the invasion is very high, these drugs have to be repeated after 15 - 20 days, and in order to prevent severe intoxication, it is necessary to use them even more than once in a single dose. All albendazole drugs are administered orally to animals, the amount of their application to each animal species is clearly indicated in the instructions. My research also shows that there are still no drugs that are 100 percent effective against young fascioliasis that trigger an acute course of fasciolosis. The strongest of them can kill young fasciolas only from 5 to 6 weeks. Accordingly, when using drugs with such potency - rolenol, kombitrem and other drugs against acute and mixed currents of fasciolosis caused by $\mathrm{F}$. gigantica, it is advisable to re-dewate sheep a second time after 40-50 days (depending on the type of fasciola). . In cattle, it is recommended to use albendazole for secondary anesthesia. It is also recommended to use a single dose of rolenol and combitrems against sheep fasciolosis from new drugs that are highly effective in acute and mixed fasciolosis. In this case, rolenol is administered intramuscularly in the amount of $1.0 \mathrm{ml}$ per $10 \mathrm{~kg}$ of body weight, and kombitrem is administered orally at the rate of $1.0 \mathrm{~g}$. 
In the treatment of acute or mixed flows of fasciolosis can also be used drugs rafoxanide, ursovermit, fazinex, fascoverm, clozantel.

Treatment of fasciolosis is carried out at the time of the disease. In the treatment of its acute and mixed currents, in addition to special drugs, symptomatic treatment is also required. These treatments are aimed at restoring the liver function of the animal, preventing and restoring disorders of the circulatory, respiratory, and digestive systems. In addition, it is necessary to provide animals with highly nutritious, rich in vitamins and minerals.

\section{References}

1. Ergashev E.H., Abduraxmonov T.A. Chorva mollarining gelmintozlari. O‘quv qo'llanma. Toshkent, «Mehnat», 1992 yil.

2. Haqberdiev P.S., Qurbanov Sh.X. Parazitologiya fanidan amaliy va laboratoriya mashg‘ulotlari. O`quv qo'llanma. Toshkent, 2015 yil.

3. Ergashev E.H. va boshqalar. Umumiy parazitologiya. O‘quv qo‘llanma. Samarqand, 1999 yil.

4. Абуладзе К.И. Паразитология и инвазионные болезни животных. Учебники и учебные пособия. Москва, «Агропромиздат», 1990 год.

5. Шустрова М.В. Паразитология и инвазионные болезни животных. Учебник. Россия, «Колос», 2006 год.

6. Ятусевич А.И. Паразитология и инвазионные болезни животных. Учебник. Минск, «ИВЦ Минфина», 2017 год. 